\title{
Surface micromachining of unfired ceramic sheets
}

\author{
Jonathan M. Rheaume $\cdot$ Albert P. Pisano
}

Received: 10 August 2010/ Accepted: 8 November 2010/Published online: 28 November 2010

(C) The Author(s) 2010. This article is published with open access at Springerlink.com

\begin{abstract}
Conventional surface micromachining techniques including photolithography and both wet and dry etching have been directly applied to an unfired sheet of yttria-stabilized zirconia ceramic material. Reversible bonding methods were investigated for affixing unfired ceramic samples to silicon handle wafers in order to perform photolithography. Three types of photoresist were investigated. Thin film photoresist allowed a line-width feature size of $8 \mu \mathrm{m}$ to be obtained. Thick film photoresist exhibited a coverage gradient after being spun on. Chemical etching was successfully performed isotropically with concentrated hydrofluoric acid. A dry thick film resist applied by lamination provided coverage during plasma etching. Neither an oxygen plasma nor a mixture of sulfur hexafluoride and oxygen plasma proved successful at etching the unfired ceramic. Embossing was performed on the meso-scale with feature shrinkage of approximately $45 \%$ after sintering.
\end{abstract}

\section{Abbreviations \\ HTCC High temperature cofired ceramic \\ LTCC Low temperature cofired ceramic \\ $\mathrm{R}_{\mathrm{a}} \quad$ Average surface roughness \\ YSZ yttria-stabilized zirconia}

\section{Introduction}

Since the inception of the tape-casting process in 1961 (Park 1961), unfired ceramic tapes and sheets are

J. M. Rheaume $(\bowtie) \cdot$ A. P. Pisano

University of California, Berkeley, USA

e-mail: jrheaume@alum.mit.edu common starting materials for electrochemical gas sensors and for high temperature electronic devices. The application of microfabrication techniques to unfired ceramic sheets according to the principles of microsystems technologies holds potential for the mass production of microscale fuel cells for power production and the manufacturing of solid state sensors for exhaust gas analysis (Wilcox et al. 2002). The shorter diffusion path of these devices is expected to lower their operating temperature and in the case of sensors, improve the response time. Further applications in semiconductor device packaging may be possible.

Unfired ceramic sheets consist primarily of ceramic particles which make up approximately $80-90 \%$ of the weight of the sheet and roughly $50 \%$ by volume. The balance of the sheet consists of the following organic materials: binder, plasticizer, dispersant, and deflocculant (Hong 2006). The organics allow the ceramic powders to dissolve in a slurry for tape-casting and they imbue desirable mechanical properties to the sheet for subsequent processing.

Literature on microfabrication techniques is abundant (Jaeger 2002; Madou 2002), especially on silicon processing (Moore 1965; Noyce 1961). Papers that deal with microfabrication techniques applied to unfired (green) ceramic sheets generally deal with the formation of vias for multilayered cofired ceramics using a laser (Imen and Allen 1999) or an electron beam (Yau et al. 1991). A solvent jet process has also been demonstrated for this purpose (Gongora-Rubio et al. 2001). Additional technologies have been developed to form unfired ceramic sheets including micro extrusion (van Hoy et al. 1998), micro casting of slurry on photoresist (Wilcox and Burdon 2002), stereolithographic printing (Zhang et al. 1999), micro injection molding (Petronis et al. 2001; Piotter et al. 2003), 
and micro embossing (Knitter et al. 1996; Shan et al. 2008a). One particularly innovative approach involved the use of photo-polymerizable binders mixed with ceramic particles to directly shape the bulk of an unfired ceramic film (Lee et al. 1986).

Photolithography (Levinson 2005) and etching (Williams and Muller 1996) have been applied to fired and polished ceramic material to pattern thin films (Young and Knickerbocker 1991). These techniques have also been applied to partially sintered low temperature cofired ceramic (LTCC) (Gongora-Rubio et al. 2001), however, the application of these techniques to unfired high temperature cofired ceramic (HTCC) sheet is generally lacking from the literature. An investigation of photolithography and etching on HTCC green sheet forms the basis of this inquiry. Etching is thought to occur by chemical attack of the organic content in the unfired sheet and not the ceramic particles, which are very stable. In addition, an investigation of meso-scale embossing of unfired ceramic sheet has been undertaken. Meso-scale features measure $>10 \mu \mathrm{m}$ (Gongora-Rubio et al. 2001).

Other microfabrication processes such as ion implantation (Rimini 1995), thin film deposition (Smith 1995), and chemical mechanical polishing (Oliver 2004) have generally not been investigated for unfired ceramic material in the literature. Ion implantation applies to electronic semiconducting materials, but many common ceramics such as alumina and yttria-stabilized zirconia are not semiconducting. Thin film deposition on unfired ceramic is impractical due to shrinkage during the firing step leading to delamination. The chemistry of chemical mechanical polishing is different for unfired ceramics than for silicon systems. For these reasons, these microfabrication techniques are not addressed here.

In the following, findings on the application of selected microfabrication methods directly to unfired ceramic material are reported, including reversible bonding, photolithography, both wet and dry etching, and mesoembossing. This fundamental work may be applied towards device fabrication. Unfired ceramic samples were mounted on $4^{\prime \prime}$ wafers using reversible bonding techniques. The wafers and samples were fed into coating tracks that dispense photoresist. The samples were subsequently exposed using contact photolithography, followed by development, etching, and photoresist removal. Either chemical or plasma etching were performed. Lastly, a study of mesoembossing was carried out.

\section{Experimental}

A ceramic sheet was obtained that was fabricated by a tape casting procedure. The unfired sheet consisted in majority of zirconia powder partially stabilized by $8 \%$ yttria by weight (MEL Chemicals), $<1 \%$ alumina by weight (AL-160SG, Showa Denko), polyvinyl butyral binder (Butvar B-98, Solutia Inc.), and ethanol and xylenes. The addition of $\mathrm{Al}_{2} \mathrm{O}_{3}$ reduces the grain boundary resistance by scavenging $\mathrm{SiO}_{2}$ and forming mullite $\left(\mathrm{Al}_{6} \mathrm{Si}_{2} \mathrm{O}_{13}\right)$ upon sintering, which migrates into grain interiors where they have a small influence on conductivity (Barsoukov and Macdonald 2005). A proprietary combination of binders and dispersants were also used. The organic content including solvents comprised circa $35 \%$ of the weight of the feedstock materials for the green ceramic sheet. When dry, the green sheet measured $230 \mu \mathrm{m}$ thick. Circles of unfired ceramic material were punched using cork borers of several different diameters of approximately $1 \mathrm{~cm}$.

\subsection{Reversible bonding}

In order to utilize microfabrication tools, the unfired ceramic samples were affixed to 4 " silicon "handle" wafers using the following bonding agents: thermal release tape, photoresist, thermally conductive paste, or organic solvents. In addition, some investigations were performed with Aquabond ${ }^{\mathrm{TM}}$, a thermally activated adhesive.

First the wafers were cleaned of organics by immersion in a heated sulfuric acid and hydrogen peroxide (piranha) bath for $10 \mathrm{~min}$, rinsed in deionized water, and dried. The native oxide layer was not removed. Then adhesives were applied as described below.

\subsubsection{Thermal release tape}

Revalpha ${ }^{\circledR}$ double-sided $150^{\circ} \mathrm{C}$ Nitto Denko) was adhered to the green sheet. A cork borer was used to cut out samples of approximately $1 \mathrm{~cm}$ diameter. The samples were then affixed to a $4^{\prime \prime}$ silicon wafer.

\subsubsection{Photoresist as binder}

Unfired ceramic samples were coated with hexamethyldisilane (HMDS, 98\%, Alfa Aesar) in a vacuum oven in order to promote adhesion of the g-line positive photoresist (OCG 825, Olin Microelectronic Materials) that was subsequently applied as a binding agent. An SVG 4" coating track spun photoresist at 2,200 RPM resulting in a $2 \mu \mathrm{m}$ film. No softbake was employed. The ceramic samples were placed on the surface and pressed into place with wafer tweezers or a glass slide. The wafer and the attached green ceramic sample were placed in a vacuum oven at $120^{\circ} \mathrm{C}$ and pumped down to 6 mTorr to remove bubbles and to harden the photoresist. 


\subsubsection{Thermally conductive paste}

Cool-Grease $^{\mathrm{TM}}$ (CGR7016, AI Technology, Inc.) was applied sparingly to green sheet samples and placed on a wafer preheated at $50^{\circ} \mathrm{C}$ for $2 \mathrm{~min}$. The sample was pressed in place using a glass slide, followed by $10 \mathrm{~min}$ on a hotplate at $50^{\circ} \mathrm{C}$. Excess grease was dabbed away using a swab.

\subsubsection{Organic solvents}

Two drops each of acetone, methanol, and ethanol were applied to a $4^{\prime \prime}$ wafer. An unfired ceramic sample was immediately placed on top of the area wetted by solvent. The solvent was allowed to dry for $10 \mathrm{~min}$ then driven off by placing the wafer and samples on a hotplate at $90^{\circ}$ for $5 \mathrm{~min}$. The experiment was later repeated for methanol at a temperature of $60^{\circ} \mathrm{C}$.

\subsubsection{Aquabond ${ }^{T M}$}

Aquabond $65^{\mathrm{TM}}$, a thermoplastic adhesive, was heated according to the manufacturer's instructions and used to secure unfired ceramic samples to a $4^{\prime \prime}$ wafer.

\subsection{Photolithography}

In order to pattern surface features such as trenches or electrodes, photolithographic methods were employed. Three photoresists were investigated: thin film, thick film, and dry thick film. A Karl Suss MA6 mask aligner equipped with a mercury bulb was used for exposure.

\subsubsection{Thin film photoresist}

G-line positive photoresist (OCG 825) was spun onto an unfired green sheet at 5,000 RPM without any previous HMDS surface treatment. After softbake on a hotplate at $95^{\circ} \mathrm{C}$ for $60 \mathrm{~s}$, contact photolithography was performed for $6.5 \mathrm{~s}$ at $20 \mathrm{~mW} / \mathrm{cm}^{2}$ peak intensity. No post exposure bake step was carried out. The photoresist step height on the unfired ceramic was measured was measured with a stylus profilometer (Alpha-Step IQ). Development proceeded by immersion in OCG 934 developer for $30 \mathrm{~s}$ with intermittent agitation followed by rinsing in deionized water. The sample was not hardbaked.

\subsubsection{Thick film photoresist}

Thick film photoresists were investigated because of their utility as a mask during protracted period of etching. SPR220 photoresist (Shipley Microelectronics) was spun onto a ceramic by a coating track (SVG 8626) at 1,800 RPM and softbaked at $115^{\circ} \mathrm{C}$ on a hotplate for $5 \mathrm{~min}$. The resulting photoresist film measured approximately $10 \mu \mathrm{m}$ in diameter, but coverage was uneven. In addition, bubbles were readily visible in the photoresist (Fig. 1).

The bubbles and uneven coverage prompted further experimentation. It was hypothesized that surface roughness affected the wetting of the green samples, which led to problems with coverage. Surface roughness is characterized by the amplitude parameter, $R_{a}$, which is the arithmetic average of absolute values of surface heights a surface measured by a stylus profilometer.

$R_{a}=\frac{1}{n} \sum_{i=1}^{n}\left|y_{i}\right|$

To reduce bubble formation, vacuum treatment and surface smoothing were employed. Vacuum treatment consisted of placing unfired ceramic samples coated with resist in a vacuum chamber under 3 mTorr vacuum for 15 min in an effort to rid the samples of bubbles.

Surface smoothing involved several methods that aimed to reduce the surface roughness of the surface of the unfired ceramic sheet: (1) pressing in an uniaxial press, (2) inducing reflow of organics by heating the green sheet, (3) smoothing surface by chemically inducing reflow using a solvent, and (4) depositing an intermediate layer of thin film photoresist. These methods are described below. The surface roughness was measured after each treatment with a stylus profilometer.

(1) Uniaxial press: samples were pressed uniaxially for $30 \mathrm{~s}$ at $6,000 \mathrm{lbf}$

(2) Reflow by heating: samples that received thermal treatment were placed in a furnace at various temperatures $\left(70^{\circ} \mathrm{C}, 90^{\circ} \mathrm{C}, 120^{\circ} \mathrm{C}, 150^{\circ} \mathrm{C}, 170^{\circ} \mathrm{C}\right.$, and $190^{\circ} \mathrm{C}$ ) for $15 \mathrm{~min}$ followed by an equal amount of time for cooling

(3) Reflow by solvent: one drop of methanol was added to the surfaceallowed to dry in air for $5 \mathrm{~min}$, dried at $70^{\circ} \mathrm{C}$ for an additional $5 \mathrm{~min}$, and re-measured using the stylus profilometer. Once again, the average

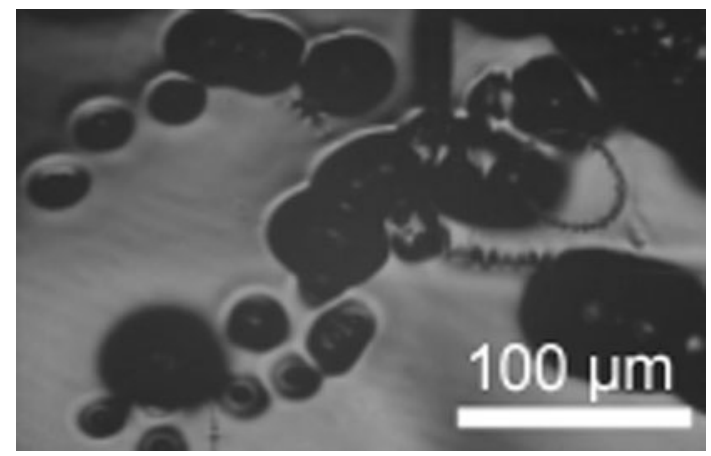

Fig. 1 Bubbles in SPR-220 photoresist on unfired ceramic surface 
surface height parameter, $\mathrm{R}_{\mathrm{a}}$, was calculated to determine surface roughness. The surface roughness parameters of the three trials were averaged

(4) Intermediate photoresist layer: a film was spun on at high speed $(5,000 \mathrm{rpm})$ to fill in surface irregularities for the subsequent application of thick film photoresist. Two types of photoresist were investigated: OCG 825 g-line thin film photoresist and SPR-220 thick film resist

The samples with the intermediate layer of thin film resist were subsequently coated with thick film photoresist. Contact lithography was performed on them with a Karl Suss photolithography tool for $15 \mathrm{~s}$ at $20 \mathrm{~mW} / \mathrm{cm}^{2}$ peak intensity. Following a hold time of $30 \mathrm{~min}$ and a post exposure bake at $115^{\circ} \mathrm{C}$ hotplate for $6.5 \mathrm{~min}$, development took place in a tank using LDD-26 W developer (RohmHaas) followed by rinsing in deionized water.

\subsubsection{Dry thick film photoresist}

DuPont Riston ${ }^{\circledR}$ dry film negative photoresist FX930 measuring $30 \mu \mathrm{m}$ in thickness was applied to the sample mounted on the handle wafer according to the manufacturer's instructions (DuPont 2003). Contact photolithography was performed by exposing for $6.0 \mathrm{~s}$ at peak intensity of $20 \mathrm{~mW} / \mathrm{cm}^{2}$. The photoresist was developed in a $1 \%$ solution of potassium carbonate (anhydrous, 99\%, Alfa Aesar) for $3 \mathrm{~min}$.

\subsection{Etching}

Both wet chemical etching with hydrofluoric acid and dry plasma etching with oxygen and sulfur hexafluoride were investigated.

\subsubsection{Wet chemical etching}

An etching solution consisting of CMOS grade hydrofluoric acid (HF, 49\%, J.T. Baker) was used to etch an unfired ceramic sample that was reversibly bonded to a wafer by photoresist (OCG 825). Photoresist height and trench depth were measured with a stylus profilometer.

\subsubsection{Dry plasma etching}

Unfired ceramic samples were investigated in either an oxygen plasma or in a sulfur hexafluoride plasma using a Plasma-Therm PK-12 reactive ion etching apparatus. For the oxygen plasma, the oxygen flow was $50 \mathrm{sccm}$, power was $200 \mathrm{~W}$, and duration was $6 \mathrm{~min}$. The etching was interrupted to characterize the samples at $2 \mathrm{~min}$ intervals. The sulfur hexafluoride plasma contained $10 \%$ oxygen; the conditions were $60 \mathrm{sccm}$ of $\mathrm{SF}_{6}, 6 \mathrm{sccm}$ of $\mathrm{O}_{2}$ at $200 \mathrm{~W}$ power for $5 \mathrm{~min}$.

\subsection{Embossing}

Unfired ceramic samples of PSZ were embossed with wires of the following nominal diameter $25,50,57,60,100$, and $127 \mu \mathrm{m}$. Each wire was pressed into a sample of unfired ceramic sheet. The sheets measured approximately $1 \mathrm{~cm}$ in diameter and were double thickness to avoid slicing through the sheet with the wire. Samples of individual sheet thickness were bonded together with a drop of ethanol. After drying, samples were pressed together for $30 \mathrm{~s}$ at 3 metric tons. Mylar sheets were inserted between the press and the samples to avoid sticking. Following pressing, the samples were sintered by firing to $1,500^{\circ} \mathrm{C}$ for $5 \mathrm{~h}$ using a low initial thermal ramp rate to drive off organic species.

\section{Results and discussion}

Upon identification of appropriate temporary bonding agents to affix the unfired ceramic sheet substrates to the silicon wafer, further investigations of photolithography, embossing, and etching were possible.

\subsection{Reversible bonding}

Unfired ceramic sheets were reversibly bonded onto handle wafers. This was performed successfully with photoresist, methanol, and Aquabond $65^{\mathrm{TM}}$ as described below.

\subsubsection{Thermal release tape}

Revalpha ${ }^{\circledR}$ thermal release tape was difficult and time consuming to cut. Removal of the transparent plastic backing film was not trivial. Although the tape generally adhered well to the silicon wafer substrate, the tape provided poor adhesion with the unfired ceramic due to the high surface roughness of the sample. The samples regularly detached during processing steps, making this method inappropriate for use. The tape itself, however, was easy to remove from the silicon wafers using a hotplate.

\subsubsection{Photoresist as binder}

G-line photoresist ( $2 \mu \mathrm{m}$ film) is easy to apply using the coating tracks. Photoresist provides better adhesion than thermal tape, although it can be somewhat difficult to remove using photoresist stripper. The long soak time in the strip bath tends to swell and soften the unfired sheet, distorting features. 


\subsubsection{Thermally conductive paste}

Cool-grease ${ }^{\mathrm{TM}}$ paste provides a weak, temporary bond that allows sliding of samples if provoked. The bond was not strong enough to fix a sample of unfired ceramic of $1 \mathrm{~cm}$ in diameter spinning at 5,000 rpm. The paste flowed out onto the wafer from under the unfired ceramic sample during thermal processing steps. In summary, this material did not meet processing requirements.

\subsubsection{Organic solvents}

One drop of methanol sufficed to reversibly bond the sample to a silicon wafer. After applying the methanol, the drive out of the methanol performed at $90^{\circ} \mathrm{C}$ resulted in bulging of the surface of the sample due to solvent boiling. By driving out the methanol at a temperature below the boiling temperature of the solvent $\left(\mathrm{T} \leq 65^{\circ} \mathrm{C}\right.$ for methanol), bulging did not occur. The unfired ceramic sample was removed from the wafer with a razor blade with care not to damage the sample. The other solvents that were tried did not yield satisfactory results; acetone evaporated too quickly to work with, and isopropanol did not cause sufficient adhesion.

\subsubsection{Aquabond ${ }^{T M}$}

The Aquabond $65^{\mathrm{TM}}$ successfully fixed ceramic samples to a silicon wafer immersed in $49 \% \mathrm{HF}$ for $20 \mathrm{~min}$. It was not used with plasma etching because wafers in this tool sometimes reach a temperature at which the adhesive melts and flows.

\subsection{Photolithography}

Three photoresists were tested for surface-patterning using standard UV-lithography.

\subsubsection{Thin film photoresist}

Good line definition was easily obtained using the OCG 825 thin film photoresist, as shown in Fig. 2. A minimum feature size of $8 \mu \mathrm{m}$ was obtained. The surface contours of the photoresist are readily visible. Conditions that usually yield a $1.3 \mu \mathrm{m}$ film of photoresist when spun on a silicon wafer resulted in an approximately $2.5 \mu \mathrm{m}$ step height on the unfired ceramic sample.

Although this photoresist exhibited the best pattern transfer ability, the thin film was not well suited for deep etching (several microns deep).

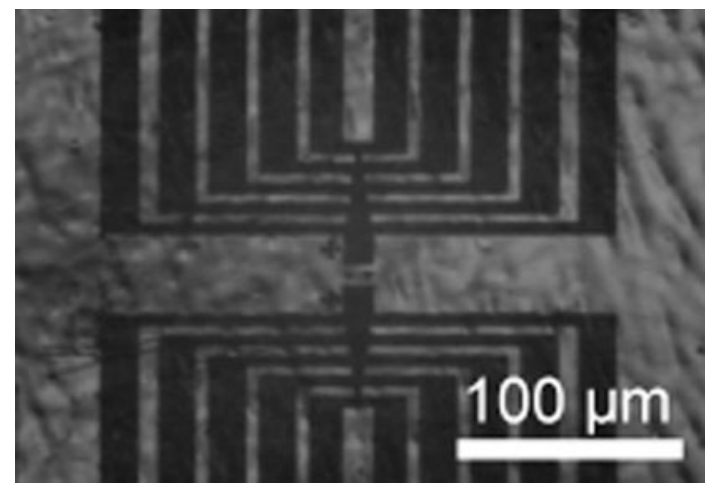

Fig. 2 Pattern in g-line photoresist on unfired ceramic surface

\subsubsection{Thick film photoresist}

The Shipley SPR-220 thick film photoresist provided numerous challenges with the unfired ceramic sheet. Although the thick film photoresist coats a smooth silicon wafer evenly and without bubbles, on the green sheet, it spun on unevenly and formed bubbles. The vacuum treatment failed to remove bubbles (Fig. 3). In fact, outgassing appears to have created more bubbles.

Coverage problems were hypothesized to result from the surface roughness of the green sheet which negatively affects wetting of photoresist. Analogously, a water droplet does not wet a leaf on account of the epicuticular cilia of varying length that impart roughness (Ren et al. 2007).

In these experiments with photoresist on the surface of unfired ceramic, surface roughness is indicated by the arithmetic average of the surface profile as expressed by the parameter, $R_{\mathrm{a}}$. An unfired ceramic sheet typically has $\mathrm{R}_{\mathrm{a}}$ of approximately $0.4 \mu \mathrm{m}$ on its smooth side compared to an $R_{a}$ of approximately $0.6 \mu \mathrm{m}$ on the rough side. This difference arises due to the tape casting process; the rough side is exposed to a doctor blade. The smooth side with the lower $\mathrm{R}_{\mathrm{a}}$ was typically used in experiments. For comparison, a silicon wafer with its native oxide layer has $R_{a}$ of approximately $0.01 \mu \mathrm{m}$.

To reduce the roughness, the following methods were employed: (1) uniaxial press, (2) reflow by heating, (3) reflow by solvent, and (4) intermediate layer of thin film photoresist. All methods succeeded in reducing the surface roughness, but only the last treatment succeeded in reducing photoresist bubble formation. Table 1 presents the results of the various treatments.

The pretreatment methods that resulted in the smoothest samples did not resolve the coverage issues. These different smoothing treatment results are discussed in more detail below.

(1) Uniaxial press: the pressing technique resulted in a large decrease in the roughness of surface height, but 

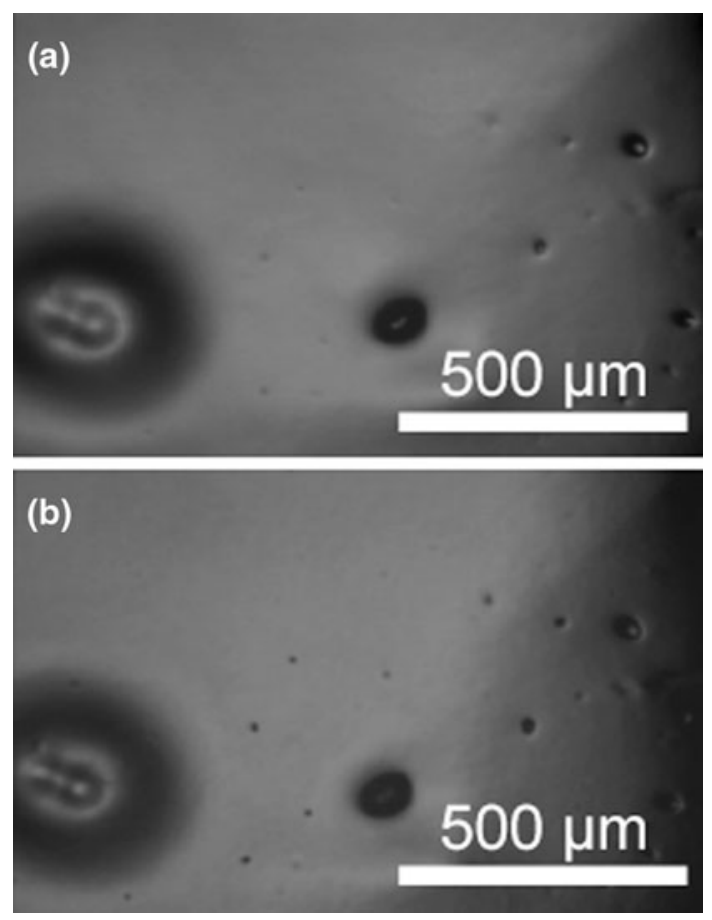

Fig. 3 Vacuum causes outgassing in Shipley 220 photoresist on unfired ceramic sheet. a Before vacuum. b After vacuum

Table 1 Surface roughness before and after smoothing treatments

\begin{tabular}{lllc}
\hline $\begin{array}{l}\text { Smoothing } \\
\text { treatment }\end{array}$ & $\begin{array}{l}\mathrm{R}_{\mathrm{a}} \text { before } \\
(\mu \mathrm{m})\end{array}$ & $\begin{array}{l}\mathrm{R}_{\mathrm{a}} \text { after } \\
(\mu \mathrm{m})\end{array}$ & $\begin{array}{l}\text { Decrease } \\
(\%)\end{array}$ \\
\hline Uniaxial press & 0.437 & 0.338 & 23 \\
Heating reflow & 0.316 & 0.312 & 1 \\
Solvent (methanol) & 0.610 & 0.293 & 52 \\
Intermediate resist & 0.391 & 0.296 & 24 \\
\hline
\end{tabular}

bubbles persisted when the SPR-220 photoresist was spun on.

(2) Reflow by heating: the samples that received thermal treatment did not show significant variation in surface roughness (Fig. 4). The change in the surface was small between $70^{\circ}$ and $190^{\circ} \mathrm{C}$. The small increase in surface roughness at $120^{\circ} \mathrm{C}$ is attributed to the outgassing of organic species from the unfired ceramic sheet. This effect was not aberrant; rather it was repeated with the identical result. As the temperature increased from $150^{\circ} \mathrm{C}$ to $190^{\circ} \mathrm{C}$, a minor decrease in the surface roughness was apparent. During the heat treatment, the ceramic samples experienced a weight loss of $9.8 \%$, which is attributed to the loss of organic species.

(3) Reflow by solvent: treatment with methanol showed a reduction in surface roughness, but bubbles still persisted in thick film photoresist after spin-on. A reduction in surface roughness can be attributed to the

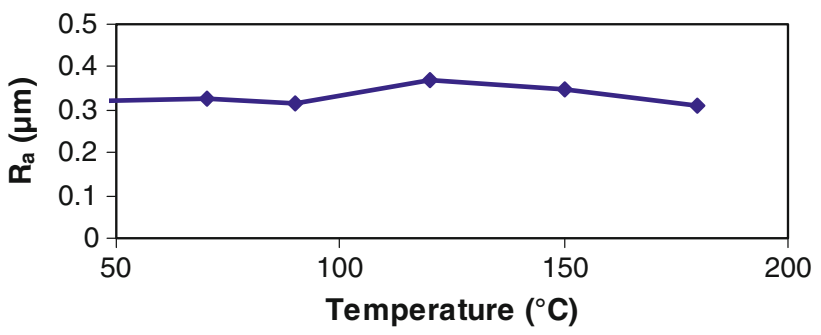

Fig. 4 Average unfired ceramic surface roughness, $R_{a}$, as a function of temperature

dissolution of organic binders and plasticizers by the solvent, causing a localized rearrangement of species resulting in a smooth surface.

(4) Intermediate layer: two different photoresists were spun on at 5,000 RPM. The g-line photoresist used as a smoothing agent succeeded in reducing the surface roughness considerably. No bubble formation was observed. For these samples, SPR-220 thick film photoresist was subsequently spun on for the purpose of photolithographic pattern transfer. Figure 5 shows the handle wafer with the unfired ceramic samples coated with an intermediate layer of thin film photoresist and a layer of thick film photoresist. Clearly the coverage gradient problem persisted, as seen in Fig. 5. A buildup of photoresist is clearly visible on the side that faces the outer edge of the wafer. A similar result was observed for all samples. This unequal coverage occurs during the spin-on process.

Figure 6 shows the coverage gradient of the SPR-220 thick film photoresist as measured by a stylus profilometer. An edge bead is clearly visible at both extremities.

When used as an intermediate smoothing layer, the SPR-220 thick film photoresist that was spun on at 5,000 RPM succeeded in eradicating bubbles, but despite the application at high angular velocity, the surface coverage gradient problem persisted. The thin film resist functioned better in this capacity.

Despite solving the bubble-formation problem with an intermediate smoothing layer of thin film photoresist, the SPR-220 thick film resist did not cover the surface of the unfired ceramic sheet evenly. Nevertheless, photolithography with this photoresist on unfired ceramic sheet was possible.

Other smoothing methods succeeded in lowering the average surface roughness $\left(\mathrm{R}_{\mathrm{a}}\right)$ more as seen in Table 1 , yet only the samples treated with an intermediate photoresist layer avoided bubble formation. These results suggest that surface roughness is not the primary factor that determines bubble formation in thick film photoresist. 

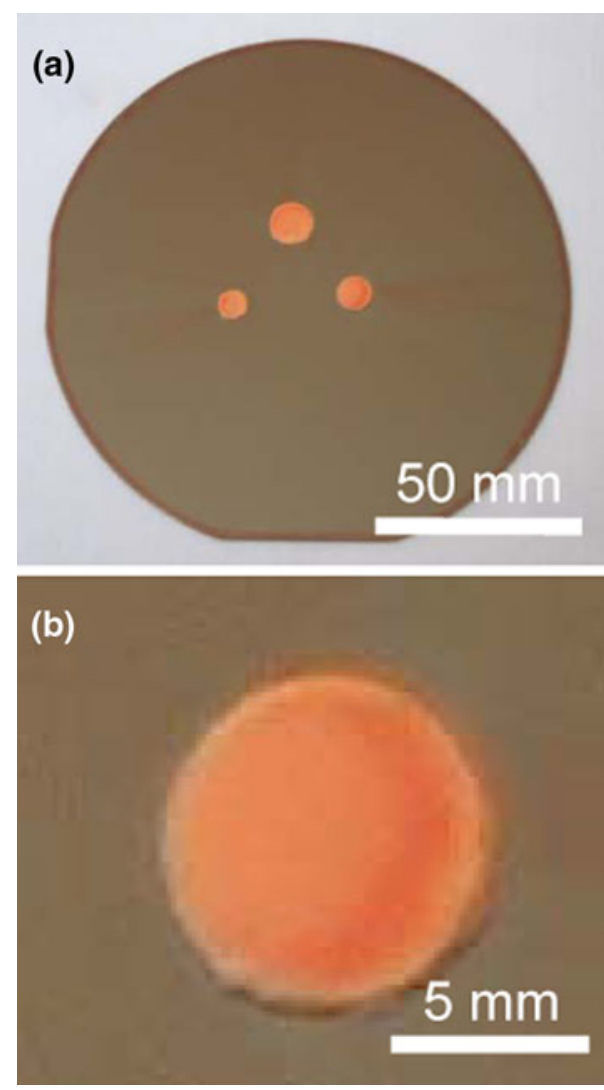

Fig. 5 a Unfired ceramics coated with thick film photoresist on 4 inch handle wafer. b Close-up view of rightmost sample

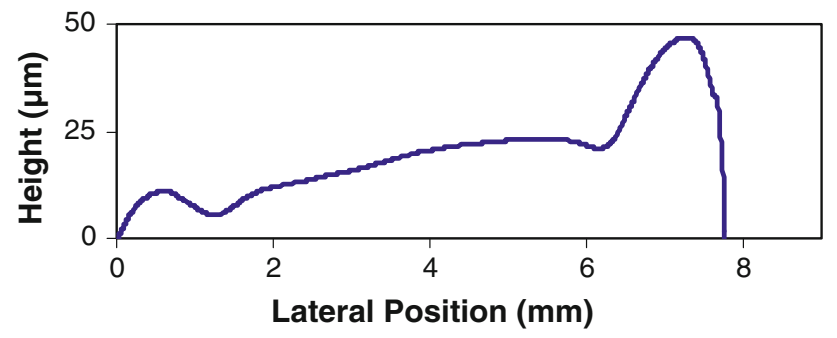

Fig. 6 Coverage gradient of thick film photoresist on unfired ceramic

\subsubsection{Dry thick film photoresist}

DuPont Riston ${ }^{\circledR}$ dry film photoresist (FX930) obviated the issues with radial coverage gradient experienced with the wet thick film resist. It coated evenly and without bubbles. The manufacturer suggests that the minimum feature size is about half the thickness of the film $(15 \mu \mathrm{m})$ (Dupont 2003). The minimum feature size is therefore smaller than what is possible using screen printing (approximately $50 \mu \mathrm{m}$ with a film of circa $20 \mu \mathrm{m}$ in height) (Hughes and Ernster 2003).

Figure 7 depicts two images of features patterned in dry film photoresist using the same mask. The image on the left is on a bare silicon wafer substrate; on the right, the film
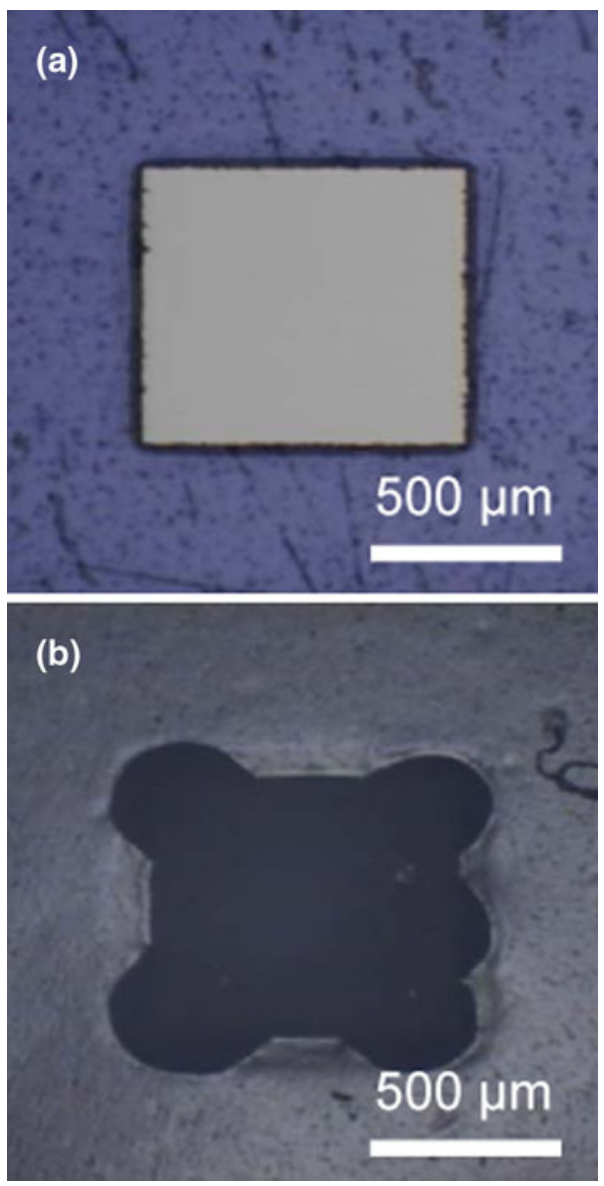

Fig. 7 Images of dry thick film photoresist patterned on a a silicon wafer and on $\mathbf{b}$ an unfired ceramic sheet

was applied to an unfired ceramic sheet. These experiments involved a feature size $(1 \mathrm{~cm})$ well above the lower limitations stated by the manufacturer. With the unfired ceramic sheet, pattern distortion was evident. The height of the unfired ceramic sheet may have caused the photoresist to be outside the depth of focus of the photolithography tool. Some samples had images that were acceptable to proceed with etching.

Gongora-Rubio et al. performed photolithographic patterning of partially sintered LTCC using laminated dry photoresist film (Riston ${ }^{\circledR}$ ). Their features measured in the tens and hundreds of microns (Gongora-Rubio et al. 2001). Their experiences and ours confirm the resolution capabilities of the dry thick film photoresist in accordance with the manufacturer's product literature (Dupont 2003).

\subsection{Etching}

G-line photoresist exhibited the best pattern transfer ability, but thick film photoresists are preferred for deep etching. Although photolithography with the thick film photoresist SPR-220 suffered from uneven coverage, it was used for 
some etching investigations. Dry thick film photoresist was also investigated.

\subsubsection{Wet chemical etching}

The hydrofluoric acid etched the SPR-220 photoresist isotropically, as expected. Figure 8 shows the progression of etch depth with time. In this diagram, the vertical position " 0 " represents the surface of the unfired sheet. The isotropic nature of the etching process is evident from the diagram. Over time, the sample begun to delaminate from the wafer, causing the sample to curl. Photoresist was used as the bonding agent.

A plot of the log of etch depth versus time is shown in Fig. 9. The etching process appears to follow a power law. An excellent fit for the trend line that fits this etching curve was obtained with $\mathrm{R}^{2}>0.99$.

Gongora-Rubio et al. (2001) discuss HF-etching of partially sintered LTCC. They first partially sintered the ceramic tape before pattern transfer in order to enable etching of the glass component using HF. LTCC contains higher glass content than HTCC which HF chemically attacks. They also reported exfoliation of the surfaces of the sheet. No exfoliation was observed in these experiments; rather exposure to $\mathrm{HF}$ caused the unfired green sheet to soften.

In a bath of $49 \% \mathrm{HF}$, the bulk of the dry film resist Riston ${ }^{\circledR}$ FX930 disintegrated, however, at the point where the resist contacted the wafer, a film of resist remained.

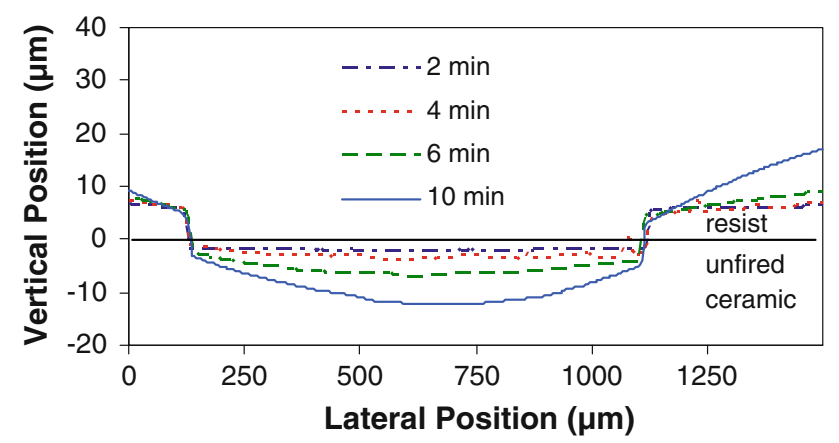

Fig. 8 HF etching profile of unfired ceramic

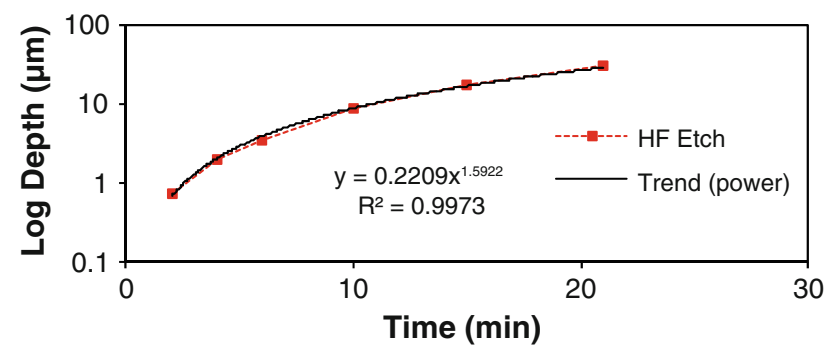

Fig. 9 Semi log plot of HF etching depth versus time
Espinoza and Santiago reported HF-etching resistance for several hours of a similar product, Riston ${ }^{\circledR}$ 9,015 (Espinoza-Vallejos and Santiago-Avilés 2000).

\subsubsection{Dry plasma etching}

Neither the oxygen plasma nor the sulfur hexafluoride plasma succeeded in producing detectible etching of the unfired ceramic sheet. The lack of etching was initially attributed to reflow of the organic materials (binder and plasticizer). An investigation of reflow, however, concluded that no reflow was observed below $190^{\circ} \mathrm{C}$, as discussed above. An alternative hypothesis is that ceramic particles insulate the underlying unfired ceramic sample from etching. The plasmas made the unfired ceramic samples dry and brittle.

The dry thick film photoresist Riston FX930 proved to be an acceptable photoresist for plasma etching. Although it degraded somewhat during etching, during the time interval that the etching was performed, it did not etch all the way through. Figure 10 depicts the result of $\mathrm{O}_{2}$ plasma etching an unfired ceramic patterned with dry thick film photoresist. It shows the profile of a ceramic green sheet at several intervals during the $\mathrm{O}_{2}$ plasma etching process. No etching of the unfired ceramic was detected. It is possible that the ceramic powders near the surface shielded the sample from chemical attack.

Although plasma etching failed to affect the unfired ceramic material, the process of stripping the photoresist had a pronounced effect on surface roughness. Figure 11 shows that the surface of the green sheet developed considerable roughness during the strip. Prior to the resist removal step, $R_{a}$ equaled approximately $0.250 \mu \mathrm{m}$, whereas afterwards the value was over $10 \mu \mathrm{m}$, an increase of almost two orders of magnitude. The surface was no longer smooth, and any micron-scale features in the green sheet would have been degraded.

The results of plasma-etching with $\mathrm{SF}_{6}$ appear in Fig. 12. Some etching of the photoresist is evident. Similar

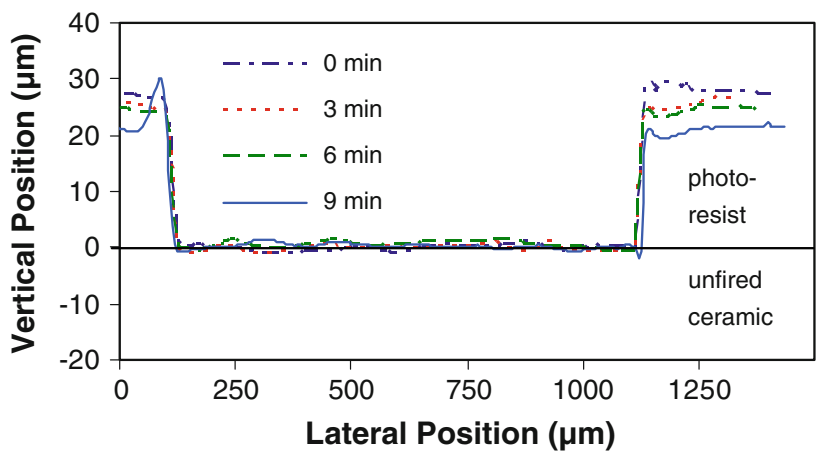

Fig. 10 Unfired ceramic sheet surface profile after $\mathrm{O}_{2}$ plasma-no etching observed 


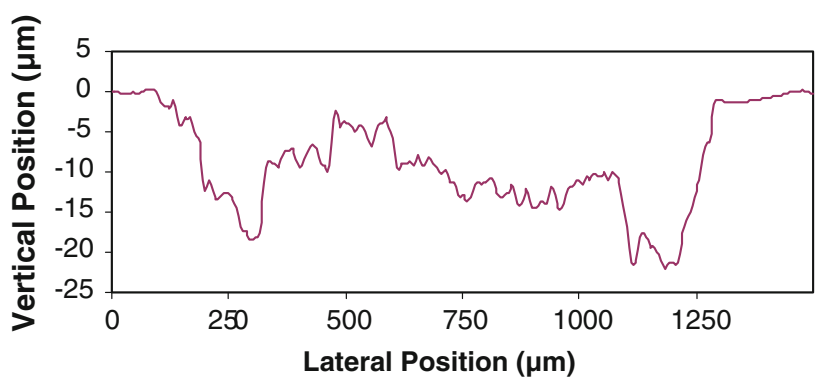

Fig. 11 Surface profile of unfired ceramic sheet roughness after photoresist strip following unsuccessful plasma etching

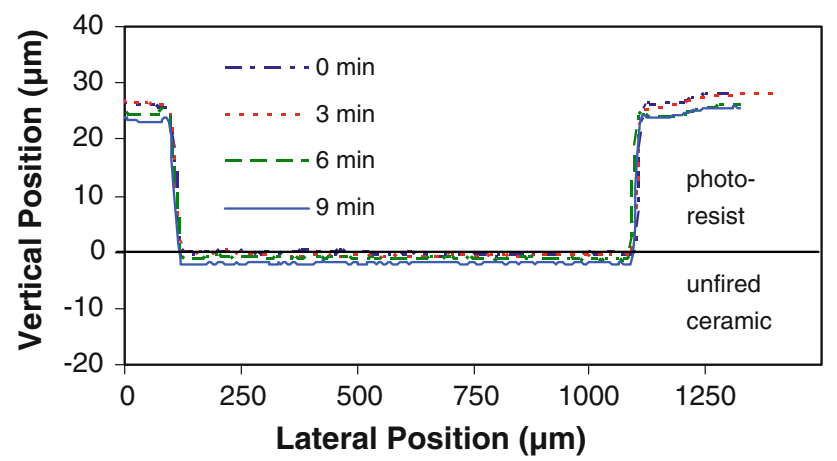

Fig. 12 Unfired ceramic sheet surface profile after $\mathrm{SF}_{6}$ plasma-no etching observed

to the experiments with $\mathrm{O}_{2}$ plasma, no etching of the unfired ceramic sheet (trench bottom) was observed. In addition, the photoresist strip step after etching also changed the surface roughness drastically (not shown). In summary, plasma-etching was not successful with unfired ceramic sheet material.

\subsection{Embossing}

Embossed wire patterns formed vias and ducts in the ceramic material. These shapes could serve as flow channels in fluidics applications. Results from the meso-scale embossing study are presented in Table 2. A reduction in feature size $>40 \%$ was observed after the sintering process.

Shan et al. (2008b) used hot embossing techniques to make channels $25-100 \mu \mathrm{m}$ wide in unfired ceramic sheet. They reported reduction in depth of 20-22\% after firing.

\section{Summary}

Surface machining processes were attempted on an unfired ceramic sheet of yttria-stabilized zirconia. Photoresist, methanol, and Aquabond ${ }^{\mathrm{TM}}$ were identified as adequate bonding agents to attach samples to handle wafers, but removal sometimes resulted in the distortion of features.
Table 2 Feature size reduction of unfired ceramic sheet due to embossing

\begin{tabular}{llll}
\hline Sample & $\begin{array}{l}\text { Nominal wire } \\
\text { diameter }(\mu \mathrm{m})\end{array}$ & $\begin{array}{l}\text { Average trench } \\
\text { depth after } \\
\text { sintering } \\
(\mu \mathrm{m})\end{array}$ & $\begin{array}{l}\text { Reduction } \\
\text { in size } \\
\text { after } \\
\text { sintering }(\%)\end{array}$ \\
\hline 1 & 25 & 11 & 56 \\
2 & 50 & 29 & 42 \\
3 & 57 & 32 & 44 \\
4 & 60 & 33 & 45 \\
5 & 100 & 61 & 40 \\
6 & 127 & 72 & 43 \\
\hline
\end{tabular}

For photoresists, no one photoresist worked ideally under all conditions. Thin film OCG-825 had the best pattern transfer of all on unfired ceramic sheet. Thick film photoresist SPR-220 exhibited a coverage gradient on unfired ceramic sheet despite spinning at high angular velocity and surface smoothing treatments. Dry photoresist film held up well during plasma etching, but the removal process drastically altered the sheet roughness. Chemical etching with HF was more effective on unfired ceramic sheet than plasma etching. HF etched unfired ceramic sheet isotropically, but the photoresist removal step distorted features. Plasma etching was unsuccessful. Wire-embossing was carried out successfully with feature shrinkage above $40 \%$. These findings may apply to a variety of unfired ceramic sheets, even ones of different ceramic composition, as long as the organic contents are similar.

In summary, processing unfired ceramic sheet using micromachining methods presented several difficulties. These results encourage future work on unfired substrates using thick film methods and on pre-sintered substrates using thin film technologies.

Acknowledgments The authors are grateful to Marilyn Kushner and Matthew Wasilik of the UC Berkeley Microlab for assisting with this research endeavor.

Open Access This article is distributed under the terms of the Creative Commons Attribution Noncommercial License which permits any noncommercial use, distribution, and reproduction in any medium, provided the original author(s) and source are credited.

\section{References}

Barsoukov E, Macdonald JR (eds) (2005) Impedance spectroscopy: theory, experiment, and applications, 2nd edn. Wiley, New Jersey

Dupont (2003) DuPont ${ }^{\mathrm{TM}}$ Riston ${ }^{\circledR}$ Special FX900 Series Data Sheet and Processing Information. Rev. 5. http://www2.dupont.com/ Imaging_Materials/en_US/assets/downloads/datasheets/fx900 series.pdf. Accessed 9 Dec 2009 
Espinoza-Vallejos P, Santiago-Avilés J (2000) Photolithographic feature fabrication in LTCC. Int $J$ Microcirc Elec Pack 23(3):286-292

Gongora-Rubio MR, Espinoza-Vallejos P, Sola-Laguna L, SantiagoAvilés JJ (2001) Overview of low temperature co-fired ceramics tape technology for meso-system technology (MsST). Sens Actuator Phys 89:222-241

Hong KS (2006) Synthesis of particle dispersion. In: Somasundaran P (ed) Encyclopedia of surface and colloid science, vol 8, 2nd edn. CRC Press, Boca Raton, pp 6208-6220

Hughes DC, Ernster SE (2003) Screen printed feature size capabilities. In: Proceedings of 2003 IMAPS Conference and Exhibition on Ceramic Interconnect Technology: the next generation, pp 58-62

Imen K, Allen SD (1999) Pulse CO laser drilling of green alumina ceramic. IEEE Trans Adv Packag 20(4):620-623

Jaeger RC (2002) Introduction to microelectronic fabrication: Vol 5 of modular series on solid state devices, 2nd edn. Prentice Hall, New Jersey

Knitter R, Günther E, Odemer C, Maciejewski U (1996) Ceramic microstructures and potential applications. Microsyst Technol 2(3): $135-138$

Lee HD, Pober RL, Calvert PD, Bowen HK (1986) Photopolymerizable binders for ceramics. J Mater Sci Lett 5(1):81-83

Levinson HJ (2005) Principles of lithography, 2nd edn. SPIE Press, Washington

Madou MJ (2002) Fundamentals of microfabrication: the science of miniaturization, 2nd edn. CRC Press, Boca Raton

Moore G (1965) Cramming more components onto integrated circuits. Electronics 38(8):114-117

Noyce RN (1961) Semiconductor device-and-lead structure. US Patent 2981877

Oliver MR (2004) Chemical-mechanical planarization of semiconductor materials. Springer, New York

Park JL Jr (1961) Manufacture of ceramics. US Patent 2966719

Petronis S, Eckert KL, Gold J, Wintermantel E (2001) Microstructuring ceramic scaffolds for hepatocyte cell culture. J Mater Sci Mater Med 12:523-528

Piotter V, Gietzelt T, Merz L (2003) Micro powder-injection moulding of metals and ceramics. Sadhana 28:299-306
Ren L, Wang S, Tian X, Han Z, Yan L, Qiu Z (2007) Non-smooth morphologies of typical plant leaf surfaces and their antiadhesion effects. J Bionic Eng 4:33-40

Rimini E (1995) Ion implantation: basics to device fabrication. Springer, New York

Shan X, Ling SH, Maw HP, Lu CW, Lam YC (2008a) Micro Embossing of ceramic green substrates for micro devices. DTIP'08 Proceedings Symposium on Design, Test, Integration and Packaging of MEMS/MOEMS 355-359, ISBN:s978-235500-006-5

Shan X, Maw HP, Tjeung RT, Ling SH, Lu CW, Jachowicz R (2008b) Microstructure formation on low temperature co-fired ceramic green substrates using micro embossing. Microsyst Technol 14:1405-1409

Smith DL (1995) Thin-film deposition: principles and practice. McGraw-Hill, New York

van Hoy C, Barda A, Griffith M, Halloran JW (1998) Microfabrication of ceramics by co-extrusion. J Am Ceram Soc 81(1):152-158

Wilcox DL, Burdon JW (2002) Methods for manufacturing patterned ceramic green-sheets and multilayered ceramic packages. US Patent 20020174935

Wilcox DL Sr, Burdon JW, Changrani R, Chou CF, Dai S, Koripella R, Oliver M, Sadler D, von Allmen P, Zenhausern F (2002) Add Ceramic 'MEMS' to the pallet of microsystems technologies. Mater Res Soc Symp Proc 687:B7.1.1

Williams KR, Muller RS (1996) Etch rates for micromachining processing. J Microelectromech Syst 5(4):256-269

Yau YW, Booke MA, Sandhu NS, Fulton JJ (1991) Microelectronics packaging processing using focused high power electron beams. Electron Comp Technol Conf 41:636-638

Young WS, Knickerbocker SH (1991) Multilayer ceramic technology. In: Buchanan RC (ed) Ceramic materials for electronicsprocessing, properties, and applications, 2nd edn. Marcel Dekker, New York, pp 489-526

Zhang X, Jiang XN, Sun C (1999) Micro-stereolithography of polymeric and ceramic microstructures. Sensor Actuator Phys $77: 149-156$ 